\title{
TRABALHO E QUALIDADE DE VIDA: ESTUDO DE CASO EM EMPRESA DE CONSTRUÇÃO CIVIL
}

\author{
Gleberson de Santana dos Santos* \\ Henrique Römer Schulz* \\ Gustavo Spiering Zanol ${ }^{* *}$ \\ Kelvin Techera Barbosa** \\ Mario Antônio Pinto da Silva Junior ${ }^{* *}$ \\ Andrey Pereira Acosta*
}

\begin{abstract}
RESUM0: 0 trabalho constitui um dos elementos mais importantes de produção social, ao passo que ao longo dos anos deixou de ser encarado apenas sob 0 aspecto econômico (homo economicus, relacionado à necessidade de subsistência), mas também tornou-se vetor de possibilidade de se alcançar reconhecimento e prestígio social, isto é, abrangendo os aspectos sociais e psicológicos. 0 objetivo deste estudo foi analisar a qualidade de vida no trabalho (QVT) em uma construtora civil da cidade de Pelotas/RS, enfatizando os aspectos relacionados a bem-estar, programas de QVT, identificação de benefícios sociais oferecidos pela organização e apontamento dos dificultadores à promoção de QVT. Metodologicamente, trata-se de uma pesquisa de caráter descritivo e abordagem qualitativa, cujo método foi um estudo de caso. Quanto ao instrumento de coleta de dados, utilizou-se o roteiro de entrevista semiestruturada que foi aplicado no mês de março de 2017 ao gestor de recursos humanos. Os resultados apontam que na percepção do entrevistado, a empresa está dedicando atenção à temática QVT, ao passo que promove ações junto aos seus empregados, ainda que de maneira incipiente. Conclui-se que a organização demonstrou percepção limitada e fragmentada sobre QVT. Observou-se que a organização adota um projeto voltado a esta temática e que se encontra em fase inicial. Como fatores limitantes em investimentos na área encontram-se 0 aspecto financeiro e a falta de apoio do gestor, a falta de tempo, demanda elevada de tarefas, metas altas e sobrecarga de trabalho, com consequente escassez de tempo e falta de interesse por parte dos próprios colaboradores.
\end{abstract}

PALAVRAS-CHAVE: Trabalho; Sentido do Trabalho; Qualidade de Vida; Construção Civil.

\section{LABOR AND LIFE QUALITY: A CASE STUDY IN A CONSTRUCTION FIRM}

\begin{abstract}
Labor is one of the most important factors in social production. Throughout time, labor superseded the economic aspect (homo economicus, related to subsistence) and became a springboard to attain acknowledgement and social prestige, involving social and psychological levels. Life quality in work (LQW) in a civil construction firm in Pelotas, Brazil, is analyzed, underscoring aspects related to well-being, LQW programs, identification of social benefits by the organization and pinpointing of LQW limitations. Current descriptive and qualitative research comprises a case study with data collected from half-structured interviews applied in March 2017 to the manager of human resources. Results show that, from the point of view of the interviewee, the firm attends LQW stance and enhances activities for its employees, albeit within fledging conditions. The firm revealed limited and fragmented perception of LQW, since only recently it turned to the theme. Limiting investment factors refer to the financial aspect and lack of support of the manager, lack of time, high rates, high objectives and work overload, with the subsequent lack of time and interest of the collaborators.
\end{abstract}

KEYWORDS: Labor; Meaning of work; Life quality; Civil construction.

Mestre em Administração, pela Universidade do Oeste de Santa Catarina (UNOESC). Docente substituto na Universidade Federal de Pelotas (UFPel) e nos cursos de pós-graduação da Faculdade de Tecnologia Senac RS, Brasil. E-mail: glebersonsantana@hotmail.com

** Discentes de Engenharia Industrial Madeireira - Universidade Federal de Pelotas (UFPel), Brasil. 


\section{INTRODUÇÃO}

0 trabalho para a humanidade constitui elemento por demais complexo por abranger aspectos culturais, sociais, econômicos, políticos e temporais, envolvendo sobremaneira as noções de saúde física e emocional, podendo ser interpretada sob uma perspectiva diacrônica, pessoal e social, como propiciadora da condição de bem-estar (CAVEDON, 2014).

Segundo Rodrigues (1999), com outros títulos e em outros contextos, mas sempre voltada para facilitar ou trazer satisfação e bem-estar ao trabalhador na execução de suas tarefas, a qualidade de vida representa objeto de preocupação da raça humana. Historicamente exemplificando, os ensinamentos de Euclides (300 a.C.) de Alexandria sobre os princípios da geometria serviram de inspiração para a melhoraria do método de trabalho dos agricultores à margem do Nilo, assim como a Lei das Alavancas, de Arquimedes, formulada em 287 a.C., veio a diminuir 0 esforço físico de muitos trabalhadores. No século $X X$, muitos pesquisadores contribuíram para 0 estudo sobre a satisfação do indivíduo no trabalho.

Entre eles destaca-se Helton Mayo, cujas pesquisas, conforme Hampton (1991), Ferreira, Reis e Pereira (1999) e Rodrigues (1999), são altamente relevantes para 0 estudo do comportamento humano e da motivação dos indivíduos para a obtenção das metas organizacionais e da Qualidade de Vida do Trabalhador, principalmente a partir das pesquisas e estudos efetuados na Western Eletric Company (Hawthorne, Chicago) no início dos anos 20, que culminaram com a escola de Relações Humanas.

Kaplan e Norton (1997) definiram o Balanced Scorecard como uma forma de avaliar o desempenho da empresa em consonância com a missão, visão e valores. Os autores propuseram quatro perspectivas: financeira, cliente, processos internos e pessoas. Neste quarto critério, é que efetivamente devem-se empregar esforços e atenção, sobretudo quando se relacionam à temática qualidade de vida no trabalho. É muito provável que funcionários motivados, capacitados e

bem remunerados passem a ter um desempenho acima da média, reduzindo custo, apresentando melhores soluções aos clientes e gerando, como desdobramento, maior vitalidade financeira, que, mais do que nunca, pode significar a sobrevivência da empresa.

Pode entender a qualidade de vida como uma proposta que visa facilitar e satisfazer as necessidades do trabalhador ao desenvolver suas atividades na organização, tendo como ideia básica o fato de que as pessoas são mais produtivas quanto mais estiverem satisfeitas e envolvidas com 0 próprio trabalho. Feigenbaum (2014) entende que a Qualidade de Vida no Trabalho - QVT é baseada no princípio de que 0 comprometimento com a qualidade ocorre de forma mais natural nos ambientes onde os funcionários se encontram intrinsecamente envolvidos nas decisões que influenciam diretamente suas atuações.

No Brasil, a preocupação com QVT surge mais tardiamente, também em função da preocupação com a competitividade das empresas, em contexto de maior abertura para a importação de produtos estrangeiros e na esteira dos programas de qualidade total (FERNANDES, 1996). De acordo com Rodrigues (1994, p.76), "a qualidade de vida no trabalho tem sido uma preocupação do homem desde o início de sua existência com outros títulos em outros contextos, mas sempre voltada para facilitar ou trazer satisfação e bem estar ao trabalhador na execução de sua tarefa". Na visão de França (2014, p. 167), QVT é entendida como a

\begin{abstract}
capacidade de administrar o conjunto de ações, incluindo diagnóstico, implantação de melhorias e inovações gerenciais, tecnológicas e estruturais no ambiente de trabalho alinhada e construída na cultura organizacional, com prioridade absoluta para 0 bem-estar das pessoas da organização. (FRANÇA, 2014, p. 167)
\end{abstract}

A QVT pode ser definida pela busca do equilíbrio psíquico, físico e social em que são respeitadas as necessidades e limitações do ser humano resultando num crescimento pessoal e profissional, sem 
traumas, afeta atitudes pessoais e comportamentais relevantes para a produtividade pessoal e grupal, tais como a motivação para 0 trabalho, a adaptabilidade a mudanças, a criatividade e a vontade de inovar (NASCIMENTO, 2012).

A importância da QVT é atribuída ao fato de 0 empregado, enquanto agente social dotado de tarefas e papéis sociais, investir seu tempo de vida em atividades laborais durante toda a fase de sua vida adulta, em tempo integral, na maioria das vezes, inclusive submetendose as dissabores do estresse ocupacional, problemas, tensões, receios e angústias, o que pode influenciar em seu estado biopsicossocial e nas suas mais diversas relações (família, escola, amigos). Trata-se de assunto importante a ser discutido, independentemente se 0 cenário econômico mostra recessão ou crescimento, perda de poder aquisitivo ou aumento do desemprego, o que suscita analisar se há relação significativa entre investimento em QVT e bem-estar dos empregados por parte da organização em contextos econômicos superavitários ou deficitários (CONTE, 2016).

França (1995) e Albuquerque e França (2015) consideram que a sociedade vive novos paradigmas de modos de vida dentro e fora da empresa, gerando, em consequência, novos valores e demandas de QVT. Para os referidos autores, outras ciências têm dado sua contribuição ao estudo do QVT, tais como

- saúde - nessa área, a ciência tem buscado preservar a integridade física, mental e social do ser humano e não apenas atuar sobre o controle de doenças, gerando avanços biomédicos e maior expectativa de vida;

- ecologia - vê o homem como parte integrante e responsável pela preservação do sistema dos seres vivos e dos insumos da natureza;

- $\quad$ ergonomia - estuda as condições de trabalho ligadas à pessoa. Fundamenta-se na medicina, na psicologia, na motricidade e na tecnologia industrial, visando ao conforto na operação;
- psicologia - juntamente com a filosofia, demonstra a influência das atitudes internas e perspectivas de vida de cada pessoa em seu trabalho e a importância do significado intrínseco das necessidades individuais para seu envolvimento com o trabaIho;

- sociologia - resgata a dimensão simbólica do que é compartilhado e construído socialmente, demonstrando suas implicações nos diversos contextos culturais e antropológicos da empresa;

- economia - enfatiza a consciência de que os bens são finitos e que a distribuição de bens, recursos e serviços deve envolver de forma equilibrada a responsabilidade e os direitos da sociedade;

- administração - procura aumentar a capacidade de mobilizar recursos para atingir resultados, em ambiente cada vez mais complexo, mutável e competitivo;

- engenharia - elabora formas de produção voltadas para a flexibilização da manufatura, armazenamento de materiais, uso da tecnologia, organização do trabalho e controle de processos.

Um dos modelos de QVT mais difundido é 0 proposto por Walton (1973), cujas dimensões são

- compensação justa e adequada: equidade salarial interna, equidade salarial externa e benefícios;

- condições de trabalho: condições físicas seguras e salutares e jornada de trabalho;

- $\quad$ oportunidade de uso e desenvolvimento das capacidades: autonomia e possibilidades de autocontrole, aplicação de habilidades variadas e perspectivas sobre 0 processo total do trabalho;

- oportunidade de crescimento contínuo e segurança: oportunidade de desenvolver carreira e segurança no emprego; 
- $\quad$ integração social no trabalho: apoio dos grupos primários, igualitarismo e ausência de preconceitos;

- constitucionalismo: normas e regras, respeito à privacidade pessoal e adesão a padrões de igualdade;

- trabalho e o espaço total da vida: relação do papel do trabalho dentro dos outros níveis de vida do empregado;

- relevância social da vida no trabalho: relevância do papel da organização em face do ambiente.

A implantação dos programas de QVT vem-se afirmando como uma alternativa para compatibilizar bem-estar, eficiência e eficácia nas organizações (FERREIRA et al., 2009). Como exemplos, algumas organizações desenvolvem programas com enfoques diversos, dentre os quais - antitabagismo, prevenção de hipertensão e diabetes, ginástica laboral e reeducação alimentar, de acordo com a problemática a que se quer combater ou difundir ou conscientizar os colaboradores (FRANÇA; OLIVEIRA, 2015).

Quanto à implementação desses programas, esbarra-se em dificultadores. Um deles é de cunho financeiro por parte da organização que encara como um "custo" e outro é a falta de interesse sobre algumas atividades realizadas com os funcionários que demonstram desinteresse em participação, como mostra 0 estudo de Baratta (1999), em que percebeu que quando se iniciam realmente as atividades, poucos comparecem para realizá-las por vários motivos.

Prochaska (1983) cita que as fases para a mudança na qualidade de vida no trabalho a serem tomadas são a pré-contemplação (0 indivíduo possui grande resistência em entender, reconhecerou modificar o problema), contemplação (conseguem identificar que possuem um problema e até consideram enfrentá-lo), preparação (o indivíduo identifica seu problema e tenta modificar seu comportamento para melhorar, mas a tentativa não é bem sucedida ou persistente), ação (0 indivíduo identifica seu problema, considera enfrentálo e faz uma tentativa bem sucedida) e manutenção (caracteriza-se pela persistência da mudança e pelo esforço em evitar recaídas).

Ainda no contexto de qualidade de vida no trabalho vale salientar que muito se reclama das condições opressivas do trabalho proveniente de necessidades de se produzir em maior escala e menor tempo. Produção (qualidade e quantidade de produtos e serviços executados em cada vez menos tempo) isso se dá em qualquer organização. Entretanto, é importante ressaltar que se trata de seres humanos, os responsáveis por esta produção, e são os seres humanos os quais formam um "ambiente" no seu inevitável inter-relacionamento.

Para Matos (1980, p. 82), "a humanização do ambiente de trabalho significa tornar o clima interno não opressivo, participativo, receptivo ao interrelacionamento cordial e cooperativo."

A QVT é uma importante ferramenta estratégica para as organizações, pois, por meio dela é possível acompanhar o comportamento dos trabalhadores; se os mesmos estiverem satisfeitos o resultado das tarefas desempenhadas terá mais qualidade, e estes estarão mais motivados para alcançar objetivos pessoais, e também, na busca por objetivos da própria organização (CONTE, 2016).

Em pesquisa sobre QVT no Brasil, nos últimos dezanos (2010-2017), observa-se que tem aumentado o número de publicações de artigos científicos em periódicos com Qualis/Capes nos dois últimos anos (2015-2016), cuja média de publicações é de em torno de 15 por ano. Do intervalo 2010-2017, a média foi de oito pesquisas científicas por ano. A pesquisa foi realizada na base de dados Spell, em que se filtrou a palavra-chave "qualidade de vida no trabalho" e limitou-se ao período supracitado. Foram pesquisados 37 artigos científicos, sendo que em 2017 (até agosto) não foram encontrados trabalhos acadêmicos. 
Quadro 1. Pesquisas sobre QVT no Brasil - últimos 7 anos

\begin{tabular}{|c|c|c|}
\hline Autor & Ano & Objetivos \\
\hline $\begin{array}{l}\text { El-Aouar, } \\
\text { Vasconcelos, } \\
\text { Veiga Neto }\end{array}$ & 2016 & $\begin{array}{l}\text { Compreender como a inserção da } \\
\text { música no ambiente de trabalho } \\
\text { contribui para alcançar a Qualidade } \\
\text { da Vida no Trabalho (QVT), na } \\
\text { perspectiva do bem-estar } \\
\text { biopsicossocial e organizacional. }\end{array}$ \\
\hline Cavedon & 2014 & $\begin{array}{l}\text { Identificar como a qualidade de } \\
\text { vida no trabalho é afetada em } \\
\text { decorrência das percepções } \\
\text { olfativas e quais as implicações na } \\
\text { saúde dos servidores que integram } \\
\text { o Departamento de Criminalística } \\
\text { vinculado ao Instituto-Geral de } \\
\text { Perícias do Rio Grande do Sul. }\end{array}$ \\
\hline $\begin{array}{l}\text { Oliveira, } \\
\text { Cavazotte, } \\
\text { Paciello }\end{array}$ & 2013 & $\begin{array}{l}\text { Examinar fatores associados aos } \\
\text { conflitos entre vida pessoal e vida } \\
\text { profissional, e suas consequências, } \\
\text { em uma amostra de trabalhadores } \\
\text { com nível superior, empregados em } \\
\text { organizações de diferentes setores } \\
\text { da economia, e que ocupam } \\
\text { predominantemente } \\
\text { gerenciais. }\end{array}$ \\
\hline Paiva, Avelar & 2011 & $\begin{array}{l}\text { Descrever e analisar como se } \\
\text { encontram configuradas as } \\
\text { variáveis de qualidade de vida no } \\
\text { trabalho na central de regulação } \\
\text { médica de um Serviço de } \\
\text { Atendimento Móvel de Urgência. }\end{array}$ \\
\hline $\begin{array}{l}\text { Guidelli, } \\
\text { Bresciani }\end{array}$ & 2010 & $\begin{array}{l}\text { Analisar a relação entre inovação } \\
\text { e Qualidade de Vida no Trabalho } \\
\text { (QVT), com foco principal no ser } \\
\text { humano, dado seu papel central } \\
\text { para a obtenção de resultados } \\
\text { organizacionais. }\end{array}$ \\
\hline
\end{tabular}

Fonte: elaborado pelos autores (2017).

0 Quadro 1 apresenta a evolução das pesquisas sobre QVT durante o período de 2010 a 2017 de trabalhos publicados em periódicos com Qualis/ CAPES estratos A1 e A2. Diante da análise do Quadro, nota-se que os estudos sobre QVT têm convergido para detectar a influência de fatores ambientais na satisfação e QVT de colaboradores de áreas distintas do segmento de mercado. Outros trabalhos encontramse centrados na repercussão do trabalho na saúde do trabalhador.

0 estudo de El-Aouar, Vasconcelos e Veiga Neto (2016) centrou-se na compreensão como a inserção de música no ambiente laboral e contribui para a obtenção da QVT, na perspectiva da percepção do bem-estar biopsicossocial e organizacional no setor de confecção de uma indústria têxtil de grande porte, localizada na cidade de Natal, Estado do Rio Grande do Norte. A pesquisa concluiu que a inserção musical proporciona bem-estar biológico, social, e, sobretudo, psicológico e organizacional aos colaboradores, contribuindo para a obtenção de QVT no ambiente laboral, além de favorecer ao aumento da produtividade por meio de um processo de mão dupla, no qual ambos se complementam. A contribuição deste estudo recai ao fato de possibilitar a identificação de atributos que não haviam sido considerados na teoria, como a Inserção da Música no Trabalho, que, além de ser apresentada como um atributo QVT, foi associada a outros a partir desse construto. Ou seja, esta investigação contribuiu para preencher a lacuna da pesquisa, qual seja entender o funcionamento da música no chão de fábrica, visto que a inserção da música nas atividades de trabalho é uma inovação institucional, que ainda é carente na teoria consistente para explicar os benefícios deste fenômeno no ambiente de fabricação.

Por sua vez, o estudo de Cavedon (2014) constatou a partir de seu objetivo que era de objetivo identificar como a QVT é afetada em decorrência das percepções olfativas e quais as implicações na saúde dos servidores que integram 0 Departamento de Criminalística vinculado ao Instituto-Geral de Perícias do Rio Grande do Sul, que o "cheiro da morte" é tido como algo difícil de ser suportado pelos servidores, sendo o cigarro utilizado para amenizar os odores pútridos. Ademais, "a ingestão de certos alimentos igualmente fica comprometida pelo cheiro e visão do local de crime. Frente a este quadro, o desenvolvimento de máscaras e indumentárias ergonomicamente adequadas faz-se mister" (CAVEDON, 2014, p. 875).

No estudo de Oliveira, Cavazotte e Paciello (2013) que centrou nos fatores associados aos conflitos entre vida pessoal e vida profissional como antecedentes e consequências dos conflitos entre trabalho e família, tendo como sujeitos pesquisados profissionais que ocupam cargos de gestão. 0 estudo 
indicou que o suporte gerencial contribui para reduzir o conflito trabalho-família enquanto que a percepção de consequências na carreira tende a promovê-lo. Com relação às consequências dos conflitos, foram encontrados impactos significativos sobre a satisfação no trabalho, 0 estresse e a intenção de deixar a empresa, mas não sobre 0 absenteísmo.

Paiva e Avelar (2011) estudaram como se encontram configuradas as variáveis de qualidade de vida no trabalho na central de regulação médica de um Serviço de Atendimento Móvel de Urgência. A pesquisa constatou nível satisfatório de qualidade de vida no trabalho, com maior destaque aos aspectos "possibilidade de crescimento", "potencial motivacional da tarefa" e "relevância social" em poder ajudar, tanto na forma direta quanto indireta, às pessoas que demandam atendimento. A pesquisa sinaliza que apesar dos resultados favoráveis, estes indicam a necessidade de melhorias quanto aos aspectos de infraestrutura, adequação de escalas e jornadas de trabalho com a realidade do município e volume de atendimentos, bem como a interlocução do Samu com os serviços hospitalares e pré-hospitalares fixos, além da conscientização da população.

Por fim, 0 estudo de Guidelli e Bresciani que se propõe analisar a relação entre inovação e QVT revela a necessária intervenção gerencial em relação ao processo de comunicação e à participação dos empregados nos temas correlatos à inovação, em função das avaliações registradas. A pesquisa ainda constatou a dificuldade de articulação de programas eficazes para comunicar e envolver os empregados. Dentre os pontos positivos para a QVT a partir da inovação destacaram-se: benefício ergonômico, confiabilidade no processo, preservação do meio ambiente e integração da equipe. Neste sentido, 0 objetivo deste estudo foi analisar a qualidade de vida no trabalho (QVT) em uma construtora civil da cidade de Pelotas/RS, enfatizando os aspectos relacionados a bem-estar, programas de QVT, identificação de benefícios sociais oferecidos pela organização e apontamento dos dificultadores à promoção de QVT.

\section{METODOLOGIA}

Metodologicamente esta pesquisa assumiu enfoque descritivo, visto que foi aprofundado o estudo em busca de informações e dados necessários sobre qualidade de vida no trabalho, pelo seu caráter subjetivo de investigação, sob a óptica do gestor de recursos humanos. A pesquisa descritiva visa desvendar e observar fenômenos, procurando descrevê-los, classificá-los e interpretá-los, passos esses utilizados para conhecer a sua natureza, composição e processos (RUDI0, 1986).

Quanto ao método utilizado, empregou-se 0 estudo de caso em uma organização da área de construção civil, localizada na cidade de Pelotas/RS. Atuando no mercado desde 1953, com cerca de 150 funcionários (engenheiro civil, engenheiro industrial madeireiros, psicólogos, funcionários para os setores administrativos e contabilista, colaboradores), a Construtora tem focado predominantemente no setor habitacional da construção civil. Atualmente tem demandado esforços no aprimoramento e desenvolvimento de projetos em habitações autossustentáveis, com sistemas construtivos racionalizados. Seu histórico contempla a execução de mais de 1 milhão de metros ${ }^{2}$ construídos em cerca de 10.000 unidades habitacionais. Para Yin (2010, p. 65), esse método consiste em "uma investigação empírica, que investiga um fenômeno contemporâneo, em profundidade e em seu contexto de vida real, especialmente quando os limites entre o fenômeno e 0 contexto não são claramente evidentes".

No que tange à abordagem da pesquisa, esta se caracterizou como qualitativa, com vistas a melhor atender 0 objetivo do trabalho que foi de analisar a qualidade de vida no trabalho, sob o enfoque da convivência, qualidade de vida, bem-estar, direitos na percepção de seu informante chave, neste caso, ao profissional responsável pelo setor de recursos humanos da organização. Por pesquisa qualitativa, Godoy (2015) argumenta que é caracterizada pela consideração tanto do ambiente fenomenológico para coleta de dados em fonte direta, quanto do pesquisador 
como instrumento fundamental. Perspectiva qualitativa, porque se buscou conhecer, compreender, descrever e interpretar determinado fenômeno. Para fenomenologia, "a compreensão da realidade se revela como um conjunto de fenômenos complexos que, embora admita correlações, é incomensurável e impossível se verificar pelas relações diretas de causa-efeito e de ser compreendida em sua plenitude" (RIBEIR0; LOBATO; LIBERAT0, 2009, p.54).

A abordagem qualitativa foi utilizada por meio da entrevista semiestruturada com o responsável pelo setor de recursos humanos da organização. A entrevista foi realizada no mês de março de 2017, gravada em recurso multimídia e transcrita, onde se pôde realizar inferências e comparar com 0 que a literatura acerca da qualidade de vida no trabalho trata.

\section{RESULTADOS}

Esta seção teve como objetivo evidenciar a percepção do gestor de recursos humanos acerca da qualidade de vida no trabalho na organização estudada, a partir da técnica de entrevista. 0 Quadro 2 sintetiza os principais resultados da pesquisa.

Quadro 2. Trabalho e qualidade de vida na perspectiva organizacional

\begin{tabular}{|c|c|}
\hline Principais questões & Principais resultados \\
\hline Conceito de QVT & Limitado \\
\hline $\begin{array}{l}\text { Benefícios sociais (legais } \\
\text { e sociais) }\end{array}$ & $\begin{array}{l}\text { Vale transporte, alimentação, } \\
\text { plano de saúde e odontológico; } \\
\text { auxílios estes variáveis de } \\
\text { acordo com a categoria a que } 0 \\
\text { funcionário pertença (apenas de } \\
\text { cunho financeiro). }\end{array}$ \\
\hline $\begin{array}{l}\text { Existência de programa(s) } \\
\text { de QVT }\end{array}$ & Sim. Em fase inicial. \\
\hline $\begin{array}{l}\text { Entraves à implantação de } \\
\text { programa(s) de QVT }\end{array}$ & $\begin{array}{l}\text { Falta de apoio do gestor, falta } \\
\text { de tempo, demanda elevada de } \\
\text { tarefas, metas altas e sobrecarga } \\
\text { de trabalho, com consequente } \\
\text { escassez de tempo, falta de } \\
\text { vontade individual. }\end{array}$ \\
\hline
\end{tabular}

Fonte: Dados da pesquisa (2018).

\section{DISCUSSÃO}

Quando questionado sobre os problemas relacionados à qualidade de vida que mais frequentemente são observados nos colaboradores, 0 entrevistado (E1) ressaltou "Falta de conhecimento nas tomadas de decisões e vícios ao utilizar equipamentos de proteção e na hora de executar a tarefa a eles determinada", reportando-se apenas aos colaboradores que trabalham diretamente na construção (pedreiros, pintores, mestres de obras etc.). No relato do entrevistado observa-se falta de domínio sobre a temática QVT e sua repercussão com a organização como todo, abarcando os profissionais que trabalham no escritório e desempenham funções indiretas à construção, demonstrando uma visão limitada do tema. Ou seja, o entrevistado restringiu a abordagem de QVT apenas aos profissionais que atuam nas funções operacionais da organização. Tal percepção distancia dos estudos de Walton (1973) e França e Oliveira (2015), os quais enfatizam que QVT deve envolver toda a organização e sua política deve ser disseminada no sentido top-down, a começar dos níveis estratégicos aos operacionais para garantir a efetividade. Além disso, abrange conteúdos como remuneração, desenvolvimento das capacidades, oportunidade de crescimento contínuo, relevância social da vida no trabalho, constitucionalismo e bemestar. Nota-se, portanto, que E1 se atém apenas ao aspecto (1) condições de trabalho e segurança em seu discurso e, em certa medida, ao aspecto (2) oportunidade de uso e desenvolvimento das capacidades.

Em termos de benefícios sociais, a organização oferece aos seus colaboradores: vale transporte, alimentação, plano de saúde e odontológico; auxílios estes variáveis de acordo com a categoria a que o funcionário pertence. Observa-se a carência no fornecimento de benefícios além das prerrogativas legais. Marras (2000, p.97) ressalta que um dos fatores para manter os funcionários motivados e satisfeitos é pelo método de estímulo por base de remunerações, informando que "o salário não é o único componente 
remuneratório de contraprestação do trabalho. Existem também os benefícios que acabam se somando àquele e compondo a chamada remuneração". Em termos de benefício de caráter motivacional, como bonificações, 0 entrevistado relatou que a organização disponibiliza 0 cartão da bandeira " $X$ ", em que "o funcionário que se destaca acumula pontos", 0 que constitui um tipo de remuneração variável.

0 entrevistado julga importante 0 investimento em QVT à organização, em vista a "para que seja uma empresa completa em todos os sentidos e com isso melhorar na qualidade do serviço" (E1). Esta visão converge com a visão de Nascimento (2012) que destaca que os benefícios de QVT relacionamse à motivação para 0 trabalho, adaptabilidade a mudanças, criatividade e vontade de inovar.

No que tange ao programa de QVT, E1 informa que a organização dispõe de um projeto em implementação, desenhado por um analista de qualidade terceirizado. Acredita-se que a presença de um projeto ainda que em fase inicial, é um ponto de partida para a formulação de programa sólido. Dessa forma, o projeto pode ser ratificado com os pressupostos de Ferreira et al. (2009) quando colocam que a implantação dos programas de QVT vêm-se afirmando como uma alternativa para compatibilizar bem-estar, eficiência e eficácia nas organizações.

0 entrevistado ainda relata que houve melhora no rendimento desses colaboradores com o projeto voltado para a saúde e qualidade de vida no ambiente de trabalho: "Sim, houve uma melhora, porém, vale ressaltar que se deve sempre ter continuidade no melhoramento da qualidade de vida" (E1). Porém, quando indagado, na sua percepção, qual 0 maior obstáculo à implantação de programas de qualidade de vida na empresa, E1 declara que é a disponibilidade financeira.

Outros entraves, segundo 0 entrevistado são a falta de apoio do gestor, falta de tempo, demanda elevada de tarefas, metas altas e sobrecarga de trabalho, com consequente escassez de tempo, falta de vontade individual, descrença quanto à atividade de QVT proposta, ou tipo de atividade ofertada que não atende à necessidade efetiva dos empregados. Estes dificultadores estão presentes também nos estudos de Baratta (1999).

Quando indagado sobre como a organização lida com a possibilidade de insatisfação e estresse no ambiente de trabalho, E1 afirma que o departamento de recursos humanos e 0 profissional "assistente social" costumam juntos ser bem ativos em relação a estes fatos, agindo pontualmente para que todos os colaboradores tenham um ambiente saudável e motivacional ao desempenharem suas funções. Aguiar e Oliveira (2016) informam que as faltas apresentadas no trabalho resultam em vários problemas para a instituição e normalmente direcionam para problemas relacionados ao ambiente de trabalho como condições inadequadas, falta de segurança e higiene no trabalho que podem propiciar acidentes e insatisfação dos profissionais. Faúndez e Gil-Monte (2017) ratificam em seu estudo forte correlação entre 0 absenteísmo e a fadiga psicológica, sobretudo nos casos de sobrecarga de trabalho por parte do empregado que acumula diversas funções, causando-lhe desinteresse na realização do trabalho.

\section{CONCLUSÃO}

0 presente trabalho teve por objetivo analisar a qualidade de vida no trabalho (QVT) em uma construtora civil da cidade de Pelotas/RS, enfatizando os aspectos relacionados a bem-estar, programas de QVT, identificação de benefícios sociais oferecidos pela organização e apontamento dos dificultadores à promoção de QVT.

Observou-se que a organização possui visão fragmentada sobre qualidade de vida no trabalho, limitando-se ao aspecto ambiental, com enfoque nas condições de trabalho e segurança e, parcialmente, nas oportunidades de uso e desenvolvimento das capacidades. Apesar da visão limitada de QVT, 0 entrevistado entende como importante a abordagem do tema para as organizações, sendo encarada como fator contributivo para melhorar na qualidade 
do serviço, ao passo que, motivado e satisfeito, 0 colaborador desempenhará suas atividades com zelo, destreza e qualidade, interferindo, por conseguinte nos resultados da organização, a partir do seu alto desempenho. Segundo a percepção do entrevistado, houve boa repercussão do projeto no desempenho dos colaboradores, porém 0 entrevistado não soube relatar em termos quantitativos tal desempenho e eficiência, tampouco relatou adoção de ferramentas de mensuração ou prática de avaliação de desempenho e sua periodicidade.

Quanto à adoção de programa, notou-se que a empresa estudada utiliza um projeto desenhado por um analista de qualidade terceirizado. Ainda em fase inicial, o projeto, assim como os investimentos em QVT têm como aspectos limitantes (1) 0 fator financeiro, em que muitas vezes ações nessa área são encaradas como "custo" e não investimento. Outros fatores dificultadores são (2) a falta de apoio do gestor, falta de tempo, demanda elevada de tarefas, metas altas e sobrecarga de trabalho, com consequente escassez de tempo e falta de interesse por parte dos próprios colaboradores.

Quanto à forma com que lida no caso de insatisfação, desmotivação e estresse no trabalho, 0 entrevistado relata que 0 setor de recursos humanos, em ação conjunta com 0 assistente social, age ativamente nesses aspectos, identificando por meio do comportamento de seus colaboradores, entendendo os fatores propulsores da "causa" e combatendo-a. Uma das ferramentas empregadas para isso é a comunicação e feedback.

Em termos de benefícios sociais, a organização oferece aos seus colaboradores: vale transporte, alimentação, plano de saúde e odontológico; auxílios estes variáveis de acordo com a categoria a que o funcionário pertence, conforme a remuneração. Para bonificar os melhores desempenhos, a organização oferece créditos em cartão, em que o colaborador acumula bônus (remuneração variável).

Este estudo é encarado como relevante, visto que a qualidade de vida do trabalho é importante no contexto organizacional, pois, por meio dela é possível ter o comprometimento dos colaboradores para a execução das tarefas.

É válido reconhecer que por se tratar de um estudo de caso, os resultados não podem ser generalizados às realidades das empresas na área de construção civil, o que constitui uma limitação da pesquisa. Outro fator limitante é a entrevista realizada apenas com um informante chave.

Como sugestão para futuros estudos, recomenda-se investigar demais organizações do segmento de construção civil; segmento este que apresentou pujança econômica nos últimos anos no Brasil para se entender como informantes chaves encaram a qualidade de vida no trabalho e avaliar se esta se encontra em seu escopo estratégico. Além disso, é importante avaliar a percepção dos colaboradores situados em níveis intermediários e operacionais acerca da QVT para se ter noção ampliada do tema e para que se possa atestar os dados dos informantes chaves, permitindo comparações.

\section{REFERÊNCIAS}

AGUIAR, G. D.A. S.; OLIVEIRA, J. R. Absenteísmo: suas principais causas e consequências em uma empresa do ramo de saúde. Revista de Ciências Gerenciais, v.13 n.18, p.95-113, 2016.

ALBUQUERQUE, L.G.; FRANÇA, A.C.L. Estratégias de recursos humanos e gestão da qualidade de vida no trabalho: 0 stress e a expansão do conceito de qualidade total. Revista de Administração, v. 33, n. 2, p. 40-51, 2015.

BARATTA, A. et al. Criminologia Crítica e Crítica do Direito Penal: introdução à sociologia do direito penal. Rio de Janeiro: Freitas Bastas, 1999. (Coleção Pensamento criminológico). p. 48.

CAVEDON, N.R. A qualidade de vida no trabalho na área da Segurança Pública: uma perspectiva diacrônica das percepções olfativas e suas implicações na saúde dos servidores. Organizações \& Sociedade, v. 21, n. 68, p. 875-892, 2014. 
CONTE, A.L. Qualidade de vida no trabalho. Revista FAE business, v. 7, p. 32-34, 2016.

EL-AOUAR, W.A.; VASCONCELOS, C.R.M.; VEIGA NETO, A.R. Quality of Working Life and Music in the Manufacturing Workplace. Organizações \& Sociedade, v. 23, n. 79, p. 656-674, 2016.

FAÚNDEZ, V.E.0.; GIL-MONTE, P.R. Prevalencia del síndrome de quemarse por el trabajo (burnout) en trabajadores de servicios en Chile. Informació psicológica, n. 91-92, p. 43-52, 2017.

FEIGENBAUM, A.V. Controle de qualidade total. 40. ed. São Paulo: Makron Books, 2014.

FERNANDES, E.C. Qualidade de vida no trabalho: como medir para melhorar. Salvador: Casa da Qualidade, 1996.

FERREIRA, A. A.; REIS, A.C.F.; PEREIRA, M.I. Gestão Empresarial: de Taylor aos nossos dias. Evolução e Tendências da Moderna Administração de Empresas. São Paulo: Pioneira, 1999.

FERREIRA, R.R. et al. Concepção e implantação de um programa de qualidade de vida no trabalho no setor público: o papel estratégico dos gestores. Revista de Administração-RAUSP, v. 44, n. 2, 2009.

FRANÇA, A.C. LIMONGI. Qualidade de vida no trabalho: conceitos, abordagens, inovações e desafios nas empresas brasileiras. Revista Brasileira de Medicina Psicossomática. Rio de Janeiro, v. 1, n. 2, p. 79-83, 1997.

FRANÇA, A.C.L. Práticas de recursos humanos: conceitos, ferramentas e procedimentos. São Paulo: Atlas, 2014.

FRANÇA, A.C.L.; OLIVEIRA, P.M. Avaliação da gestão de programas de qualidade de vida no trabalho. RAEeletrônica, v. 4, n. 1, 2015.

GODOY, A.S. Refletindo sobre critérios de qualidade da pesquisa qualitativa. Revista Eletrônica de Gestão
Organizacional (Gestão.Org), v. 3, n. 2, maio/ago., 2015.

GUIDELLI, N.S.; BRESCIANI, L.P. Inovação e qualidade de vida no trabalho: uma visão integrada da gestão a partir de estudo de caso na indústria petroquímica do Grande ABC. Revista de Administração, v. 45, n. 1, art. 5, p. 57-69, 2010.

KAPLAN, R.S.; NORTON, D.P. A estratégia em ação: Balanced Scorecard. Rio de Janeiro: Campos, 1997.

MATOS, F.G. Fator QF: ciclo de felicidade no trabalho. São Paulo: Makron Books, 1997.

MARRAS, J.P. Administração de recursos humanos: do operacional ao estratégico. São Paulo: Futura, 2000.

NASCIMENTO, F. et al. A importância da qualidade de vida no trabalho e sua influência nas relações humanas. Anuário de Produções Acadêmico-científicas dos discentes da Faculdade Araguaia, v. 2, n. 2, p. 6177, 2012.

OLIVEIRA, L.B.; CAVAZOTTE, F.S.C.N.; PACIELLO, R.R. Antecedentes e consequências dos conflitos entre trabalho e família. Revista de Administração Contemporânea, v. 17, n. 4, p. 418-437, 2013.

PAIVA, K.C.M.; AVELAR, V.L.L.M. Qualidade de vida no trabalho em uma central de regulação médica de um serviço de atendimento móvel de urgência (SAMU). Organizações \& Sociedade, v. 18, n. 57, art. 6, p. 303-321, 2011.

PROCHASKA, J.0.; DICLEMENTE, C.C.; NORCROSS, J.C. In search of how people change: Applications to addictive behaviors. American psychologist, v. 47, n. 9, p. 1102, 1983.

RODRIGUES, M.V.C. Qualidade de vida no trabalho: Evolução e Análise no nível gerencial. Rio de Janeiro: Vozes, 1994.

RIBEIRO, W. C.; LOBATO, W.; LIBERATO, R.C. Notas sobre fenomenologia, percepção e educação ambiental. Sinapse Ambiental, p. 42-65, setembro, 2009. 
RÚDIO, F. V. Introdução ao projeto de investigação científica. Petrópolis: Vozes, 1986.

WALTON, R. E. Quality of working life: whatis it? Sloan Management, v. 15, n. 1, p. 11-21, 1973.

YIN, R. K. Estudo de Caso: planejamento e métodos. 4. ed. Porto Alegre: Bookman, 2010.

Recebido em: 30/04/2018

Acesso em: 06/06/2018 